\title{
Efficacy and safety of endoscopic ultrasound-guided pancreatic duct drainage (EUS-PDD): A systematic review and meta-analysis of 714 patients
}

\section{다(1) $(-)$}

Authors

Saurabh Chandan*, 1, Babu P. Mohan*, 2, Shahab R. Khan ${ }^{3}$, Lena L. Kassab ${ }^{4}$, Suresh Ponnada ${ }^{5}$, Andrew Ofosu ${ }^{6}$, Ishfaq Bhat $^{1}$, Shailender Singh ${ }^{1}$, Douglas G. Adler ${ }^{2}$

Institutions

1 Division of Gastroenterology and Hepatology, $\mathrm{CHI}$ Creighton University Medical Center, Omaha, Nebraska, United States

2 Division of Gastroenterology and Hepatology, University of Utah School of Medicine, Salt Lake City, Utah, United States

3 Section of Gastroenterology, Rush University Medical Center, Chicago, Illinois, United States

4 Internal Medicine, Mayo Clinic, Rochester, Minnesota, United States

5 Internal Medicine, Carilion Roanoke Memorial Hospital, Roanoke, Virginia, United States

6 Gastroenterology, Brooklyn Hospital, New York, United States

submitted 2.6.2020

accepted after revision $\quad 23.7 .2020$

\section{Bibliography}

Endoscopy International Open 2020; 08: E1664-E1672

DOI 10.1055/a-1236-3350

ISSN 2364-3722

(C) 2020. The Author(s).

This is an open access article published by Thieme under the terms of the Creative Commons Attribution-NonDerivative-NonCommercial License, permitting copying and reproduction so long as the original work is given appropriate credit. Contents may not be used for commecial purposes, or adapted, remixed, transformed or built upon. (https://creativecommons.org/licenses/by-nc-nd/4.0/)

\section{Corresponding author}

Douglas G. Adler MD, FACG, AGAF, FASGE, Professor of Medicine, Director of Therapeutic Endoscopy, Director, GI fellowship Program, Gastroenterology and Hepatology, University of Utah School of Medicine, Huntsman Cancer Center, 30N 1900E 4R118, Salt Lake City, Utah 84132, United States

Fax: +1-801-581-8007

Douglas.adler@hsc.utah.edu $\bigoplus$ Supplementary material is available under https://doi.org/10.1055/a-1236-3350

\section{ABSTRACT}

Background and study aims Endoscopic ultrasound guided pancreatic duct drainage (EUS-PDD) is a minimal-invasive therapeutic option to surgery and in patients with failed endoscopic retrograde pancreatography (ERP). The aim of this review was to quantitatively appraise the clinical outcomes of EUS-PDD by meta-analysis methods.

Methods We searched multiple databases from inception through March 2020 to identify studies that reported on EUS-PDD. Pooled rates of technical success, successful drainage of pancreatic duct, clinical success, and adverse events were calculated. Study heterogeneity was assessed using $12 \%$ and $95 \%$ prediction interval.

Results A total of 22 studies (714 patients) were included. The pooled rate of technical success in EUS-PDD was $84.8 \%$ (95\% Cl 79.1-89.2). The pooled rate of successful PD drained by EUS-PDD was $77.5 \%$ (95\% Cl 63.1-87.4). The pooled rate of clinical success of EUS-PDD was $89.2 \%$ (95\% Cl 82.1-93.7). The pooled rate of all adverse events was $18.1 \%$ (95\% Cl 14.2-22.9). On sub-group analysis, the pooled technical success and clinical success of EUS-PDD from Japanese data were considerably superior (91.2\%, 83-95.6 \& 92.5\%, 83.9-96.7, respectively). The pooled rate of post EUS-PDD acute pancreatitis was $6.6 \%(95 \% \mathrm{Cl}$ 4.5-9.4), bleeding was $4.1 \%$ (95\% Cl 2.7-6.2), perforation and/or pneumoperitoneum was $3.1 \%$ (95\% Cl 1.9-5), pancreatic leak and/or pancreatic fluid collection was $2.3 \%$ (95\% Cl 1.4-4), and infection was $2.8 \%$ (95\% Cl 1.7-4.6).

Conclusion EUS-PDD demonstrates high technical success and clinical success rates with acceptable adverse events. Technical success was especially high for anastomotic strictures.

\footnotetext{
* These authors contributed equally.
} 


\section{Introduction}

Patients with an obstructed pancreatic duct (PD) can suffer from pain that can be severe. Etiologies of an obstructed pancreatic duct PD include chronic pancreatitis with inflammatory stenosis of the duct and/or papilla, obstructions due to pancreato-lithiasis, compressing pseudocysts, disconnected pancreatic duct syndrome (DPDS), and stenosis of the pancreatico-enteral anastomosis following surgery, typically a pancreaticojejunostomy created during pancreaticoduodenectomy [13].

The current mainstay of treatment is to relieve the obstruction with endoscopic retrograde transpapillary (ERP) drainage or, less commonly, surgery [1,2]. Traditionally, surgical intervention included lateral pancreatico-jejunostomy (Peustow procedure) in patients with a dilated main pancreatic duct (MPD) or pancreaticoduodenectomy (Whipple procedure) versus distal pancreatectomy [1,2]. Although surgery is effective in this setting with success rates of $65 \%$ to $85 \%$, adverse event (AE) rates of up to $30 \%$ and mortality rates up to $2 \%$ have been reported [4]. Patients who underwent prior pancreaticojejunostomy creation can have this anastomosis revised, although often at the cost of further loss of pancreatic parenchyma.

Since the first report of EUS guided pancreaticogastrostomy in 2002, endoscopic ultrasound-guided pancreatic duct drainage (EUS-PDD) has emerged as a therapeutic option in patients who have failed conventional methods of ERP-PDD [5]. EUSPDD can help avoid invasive surgery. Data on the efficacy and safety of EUS-PDD are limited [6-27]. The aims of this study were to qualitatively and quantitatively appraise the current available data on EUS-PDD by meta-analysis methods.

\section{Methods}

\section{Search strategy}

The literature was searched by a medical librarian for the concepts related to EUS-PDD. Search strategies were created using a combination of keywords and standardized index terms. Searches were run in March 2020 in ClinicalTrials.gov, Ovid EBM Reviews, Ovid Embase (1974+), Ovid Medline (1946+including epub ahead of print, in-process \& other non-indexed citations), Scopus $(1970+)$ and Web of Science $(1975+)$. Results were limited to English language manuscripts. All results were exported to Endnote where 1120 obvious duplicates were removed leaving 1744 citations. The full search strategy is available in Appendix 1. The MOOSE and PRISMA checklists were followed and are provided as Appendixes 2 and 3 [28, 29]. Reference lists of evaluated studies were examined to identify other studies of interest.

\section{Study selection}

In this meta-analysis, we included studies that evaluated the clinical outcomes of EUS-PDD. Studies were included irrespective of inpatient/ outpatient setting, follow-up time, route of access and/or drainage, presence of surgically altered anatomy, and geography as long as they provided the appropriate data needed for the analysis.
Our exclusion criteria were: (1) case reports and case series studies; (2) studies with sample size<10 patients; (3) studies performed in the pediatric population (age <18 years); and (4) studies not published in English language. In cases of multiple publications from a single research group reporting on the same patient, same cohort and/or overlapping cohorts, data from the most recent and/or most appropriate comprehensive report were retained. When needed, authors were contacted via email for clarification of possible study-cohort overlap. The retained studies were selected by two authors (BPM, SC) based on publication timing (most recent) and/or sample size of the study (largest). In situations in which a consensus could not be reached, overlapping studies were included in the final analysis and any potential effects were assessed by sensitivity analysis of the pooled outcomes by leaving out one study at a time.

\section{Data abstraction and quality assessment}

Data on study-related outcomes from the individual studies were abstracted independently onto a standardized form by at least two authors (BPM, SRK). Authors SC and LLK cross-verified the collected data for possible errors and two authors (BPM, SRK) did the quality scoring independently. The primary study authors were contacted via email as and when needed for further information and/or clarification on data.

The Newcastle-Ottawa scale for cohort studies was used to assess the quality of studies [30]. This quality score consisted of eight questions, the details of which are provided in Supplementary Table 1.

\section{Outcomes assessed}

1. Pooled rates of technical success of pancreatic duct access (defined as successful pancreatography and/or insertion of pancreatic duct wire and/or duodenal wire),

2. Pooled rate of successful drainage of the pancreatic duct (defined as resolution of MPD obstruction via drainage),

3. Pooled rate of clinical success (defined as successful clinical resolution of symptoms, such as pain)

4. Pooled rate of AEs (defined by the American Society for Gastrointestinal Endoscopy [ASGE] lexicon for endoscopic adverse events) and AE subtypes [31],

5. Pooled rate of stent-related complications (defined as stent migration and/or stent occlusion) and the need for EUS-PDD reintervention (defined as the need for repeat procedure in patients who achieved clinical success before irrespective of the presence and/or absence of stents).

\section{Statistical analysis}

We used meta-analysis techniques to calculate the pooled estimates in each case following the methods suggested by DerSimonian and Laird using the random-effects model [32]. When the incidence of an outcome was zero in a study, a continuity correction of 0.5 was added to the number of incident cases before statistical analysis [33].

We assessed heterogeneity between study-specific estimates by using Cochran Q statistical test for heterogeneity, $95 \%$ prediction interval $(\mathrm{PI})$ and the $\mathrm{I}^{2}$ statistics [33-35]. In this, values $<30 \%, 30 \%$ to $60 \%, 61 \%$ to $75 \%$, and $>75 \%$ were 
suggestive of low, moderate, substantial, and considerable heterogeneity, respectively. The PI gives an idea about the range of dispersion of the pooled results in the wider universe, and $\mathrm{I}^{2}$ tell us what proportion of the dispersion is true vs chance.

Publication bias was ascertained, qualitatively, by visual inspection of funnel plot and quantitatively, by the Egger test [36]. When publication bias was present, further statistics using the fail-Safe $\mathrm{N}$ test and Duval and Tweedie's 'Trim and Fill' test was used to ascertain the impact of the bias [37]. Three levels of impact were reported based on the concordance between the reported results and the actual estimate if there were no bias. The impact was reported as minimal if both versions were estimated to be same, modest if effect size changed substantially but the final finding would still remain the same, and severe if basic final conclusion of the analysis is threatened by the bias [38].

Meta-regression analysis was attempted, when feasible, to study the effects of patient variables on the pooled outcomes. Knapp-Hartung two-tailed $P<0.05$ was considered statistically significant and $R^{2}$ value was calculated to study the goodnessof-fit. All analyses were performed using Comprehensive MetaAnalysis (CMA) software, version 3 (BioStat, Englewood, New Jersey, United States).

\section{Results}

\section{Search results and population characteristics}

A total of 22 studies were included in the final analysis [6-27]. The schematic diagram demonstrating our study selection is illustrated in Supplementary Fig. 1.

A total of 714 patients were analyzed from the included studies. $55 \%$ were males. Mean age ranged from 36 years to 69 years. The pre- EUS-PDD mean main pancreatic duct diameter ranged from $3.5 \mathrm{~mm}$ to $8.1 \mathrm{~mm}$. Further details along with the population characteristics are described in Supplementary Table 1.

EUS-PDD was attempted via the following approaches: (1) ERP-EUS rendezvous procedure if the papilla can be reached endoscopically with successful advancement of a guidewire to the bowel lumen, either through the papilla or through an anastomosis. Endoscopic retrograde cholangiopancreatography (ERCP) using the rendezvous guide-wire can then be performed; (2) primary transgastric or transduodenal drainage with ante- or retrograde outflow if the papilla or the anastomosis cannot be reached endoscopically. PDD in these situations is achieved via transmural fistula creation followed by dilation and stent placement; or (3) internal antegrade drainage if the papilla cannot be reached but the stenotic ductal segment can be passed by the guidewire, in which case the stent is pushed into the small intestine through the ampulla or the anastomosis.

\section{Characteristics and quality of included studies}

There were no population-based studies. Six studies were based on multicenter data $[7,11,13,22,24,26]$. The detailed study quality evaluation is presented in Supplementary Table 3. Based on the New-Castle Ottawa scoring system, five studies $[7,10,22,24,27]$ were considered to be of high quality and 17 studies $[6,8,9,11-21,23,25,26]$ were considered to be of medium quality. There were no low-quality studies.

\section{Meta-analysis outcomes}

Technical success

The pooled rate of technical success in EUS-PDD was $84.8 \%$ (95\% Cl 79.1-89.2). Forest plot ( $\mathbf{F i g . 1}$ ). The pooled rate of technical success from multicenter data was $87.5 \%(95 \% \mathrm{Cl}$ 77.7-93.4) and from single-center data was $83.5 \%(95 \% \mathrm{Cl}$ 76.1-88.9). The pooled rate of technical success of studies published as full manuscripts was $84.4 \%$ (95\% Cl 77.4-89.5) and of studies in abstract form was $86.5 \%$ (95\% Cl 74.3-93.5). The pooled rate of technical success when evaluating follow up time $>12$ months was $84.1 \%(95 \% \mathrm{Cl} 71.8-91.6)$ and $<12$ months was $92.6 \%$ (95\% Cl 84.4-96.6) (

\section{Successful PD drainage}

The pooled rate of successful PD drainage by EUS-PDD was $77.5 \%$ (95\% Cl 63.1-87.4) (> Fig. 2).

The pooled rate of successful PD drained from multi-center data was $87.2 \%(95 \% \mathrm{Cl} 69.5-95.3)$ and from single center data was $70.2 \%$ (95\% Cl 52.1-83.5). The pooled rate of successful PD drained when evaluating follow up time $>12$ months was $79.5 \%(95 \% \mathrm{Cl} 47.7-94.3)$ and $<12$ months was $84.2 \%(95 \% \mathrm{Cl}$ 53-96.2) ( Table 1).

\section{Clinical success}

The pooled rate of clinical success of EUS-PDD was $89.2 \%$ (95\% Cl 82.1-93.7)( Fig. 3).

The pooled rate of clinical success from multicenter data was $90.2 \%(95 \% \mathrm{Cl} 77.9-96)$ and from single center data was $88.3 \%$ (95\% Cl 79-93.8). The pooled rate of clinical success of studies published as full manuscripts was $89.6 \%$ (95\% Cl 81.2-94.5) and of studies in abstract form was $88.8 \%$ (95\% Cl 67.7-96.8). The pooled rate of clinical success when evaluating follow up time $>12$ months was $86.4 \%(95 \% \mathrm{Cl} 71.9-94.1)$ and $<12$ months was $85.3 \%$ (95\% Cl 70.3-93.5) (

\section{Adverse events}

The pooled rate of all AEs was $18.1 \%$ (95\% Cl 14.2-22.9) ( $\triangleright$ Fig. 4). The pooled rate of AEs from multicenter data was $24.3 \%(95 \% \mathrm{Cl} 16.8-33.7)$ and from single-center data was $15.9 \%$ ( $95 \% \mathrm{Cl} 11.8-21)$. The pooled rate of AEs of studies published as manuscripts was $17.9 \%(95 \% \mathrm{Cl} 13.4-23.5)$ and of studies in abstract form was $18.2 \%$ (95\% Cl 10.8-29).

Based on the ASGE lexicon of AEs, the pooled rate of procedure-related mild AEs was $13 \%$ (95\% Cl 8.3-19.9), moderate AEs $9.9 \%(95 \% \mathrm{Cl} 6.5-14.8)$, and severe AEs was $3.9 \%(95 \% \mathrm{Cl}$ 2.5-5.9).

In terms of the specific type of AE (defined as post EUS-PDD acute pancreatitis, bleeding, perforation and/or pneumoperitoneum, pancreatic leak and/or pancreatic fluid collection, and infection), the pooled rate of post EUS-PDD acute pancreatitis was $6.6 \%$ (95\% Cl 4.5-9.4), bleeding was $4.1 \%(95 \% \mathrm{Cl}$ 2.7-6.2), perforation and/or pneumoperitoneum was $3.1 \%$ (95\% Cl 1.9-5), pancreatic leak and/or pancreatic fluid collec- 


\section{Technical success}

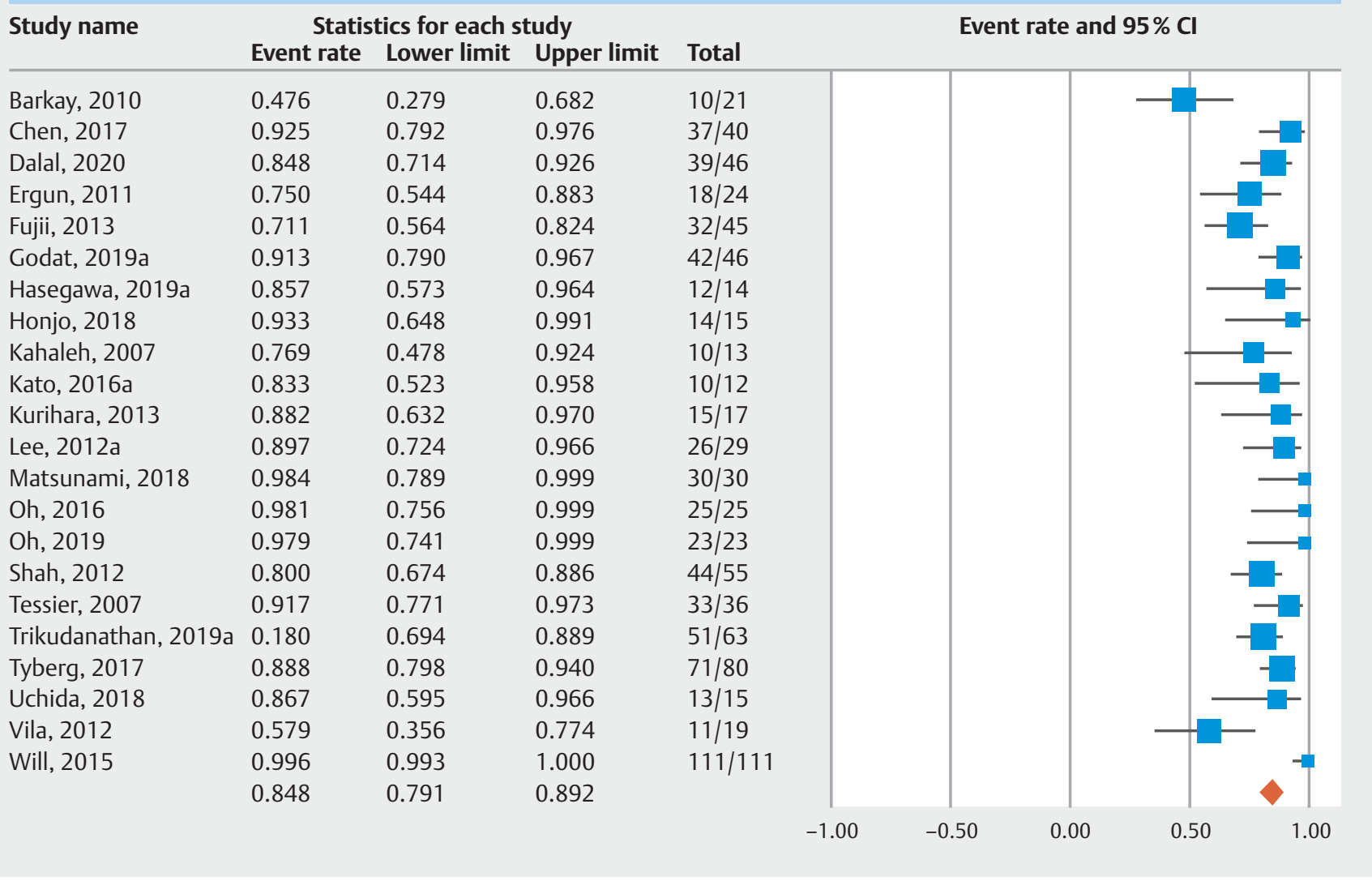

Fig. 1 Forest plot of pooled technical success.

tion formation was $2.3 \%(95 \% \mathrm{Cl} 1.4-4)$, infection was $2.8 \%$ (95\% Cl 1.7-4.6) and non-specific post-procedure abdominal pain warranting inpatient monitoring was $13.9 \%(95 \% \mathrm{Cl} 8.2-$ 22.6).

\section{Stent related}

AEs, defined as stent migration and/or occlusion, occurred in $21.3 \%$ of patients $(95 \% \mathrm{Cl} 11.5-36.2)$. The pooled rate of EUSPDD reintervention was $15.2 \%$ (95\% Cl 9.1-24.1).

\section{Meta-regression analysis}

Meta-regression analysis was performed to assess the impact on calculated pooled rates of technical success and clinical success for the following variables: chronic pancreatitis, anastomotic strictures, transmural stenting and rendezvous technique. A statistically significant two-tailed $P$ value by KnappHartung method was noticed with anastomotic strictures as a single variable $\left(P=0.03, R^{2}=0.29\right)$ on the calculated technical success. Rest of the variables did not demonstrate significant influence on the calculated technical and/or clinical success rates.

\section{Validation of meta-analysis results}

\section{Sensitivity analysis}

To assess whether any one study had a dominant effect on the meta-analysis, we excluded one study at a time and analyzed its effect on the main summary estimate. In this analysis, no single study significantly affected the outcome or the heterogeneity. The results of subgroup analysis are summarized in $>$ Table 1.

\section{Heterogeneity}

We assessed dispersion of the calculated rates using the prediction interval (PI) and $\mathrm{I}^{2}$ percentage values. The calculated PIs are reported with the pooled rates in $>$ Table 1 . Overall, none to considerable heterogeneity was noted across the analysis. Specifically, data from Japan demonstrated minimal heterogeneity with narrow prediction intervals. In addition, EUS-PDD in patients with anastomotic strictures demonstrated statistical significance when assessed as a single variable on meta-regression analysis. Therefore, study geography and clinical indication for EUS-PDD are explainable causes of heterogeneity in this analysis. 
- Table 1 Summary of pooled rates.

\begin{tabular}{|c|c|c|}
\hline Outcome & $\begin{array}{l}\text { Pooled rate ( } 95 \% \\
\text { confidence interval) }\end{array}$ & $\begin{array}{l}\text { 12; } 95 \% \text { predic- } \\
\text { tion interval }\end{array}$ \\
\hline Technical success & $\begin{array}{l}84.8 \%(79.1-89.2) \\
22 \text { studies }\end{array}$ & $61 \% ; 56$ to 96 \\
\hline - USA & $\begin{array}{l}77.5 \%(61.2-88.3) \\
4 \text { studies }\end{array}$ & $0 \% ; 38$ to 95 \\
\hline - Europe & $\begin{array}{l}85.3 \%(72-92.9) \\
5 \text { studies }\end{array}$ & $79 \% ; 11$ to 99 \\
\hline - Japan & $\begin{array}{l}91.2 \%(83-95.6) ; \\
9 \text { studies }\end{array}$ & $0 \% ; 81$ to 96 \\
\hline $\begin{array}{l}\text { Others (multiple } \\
\text { countries, Israel, } \\
\text { India) }\end{array}$ & $\begin{array}{l}82 \%(67.1-91.1) \\
4 \text { studies }\end{array}$ & $84 \% ; 4$ to 99 \\
\hline - Multicenter & $\begin{array}{l}87.5 \%(77.7-93.4) \\
6 \text { studies }\end{array}$ & $66 \% ; 41$ to 98 \\
\hline - Single-center & $\begin{array}{l}83.5 \%(76.1-88.9) \\
16 \text { studies }\end{array}$ & $58 \% ; 54$ to 95 \\
\hline - Manuscripts & $\begin{array}{l}84.4 \%(77.4-89.5) \\
17 \text { studies }\end{array}$ & $68 \% ; 48$ to 97 \\
\hline - Abstracts & $\begin{array}{l}86.5 \%(74.3-93.5) \\
5 \text { studies }\end{array}$ & $0 \% ; 63$ to 96 \\
\hline $\begin{array}{l}\text { - >12-month follow- } \\
\text { up }\end{array}$ & $\begin{array}{l}84.1 \%(71.8-91.6) \\
5 \text { studies }\end{array}$ & $64 \% ; 41$ to 94 \\
\hline $\begin{array}{l}\text { - <12-month follow- } \\
\text { up }\end{array}$ & $\begin{array}{l}92.6 \%(84.4-96.6) ; \\
6 \text { studies }\end{array}$ & $30 \% ; 52$ to 94 \\
\hline Successful PD drained & $\begin{array}{l}77.5 \%(63.1-87.4) \text {; } \\
11 \text { studies }\end{array}$ & $88 \% ; 21$ to 98 \\
\hline - Europe & $\begin{array}{l}69.2 \%(47-85) \\
4 \text { studies }\end{array}$ & $85 \% ; 2$ to 99 \\
\hline - Others & $\begin{array}{l}89.4 \% \text { (75.7-95.8); } \\
4 \text { studies }\end{array}$ & $9 \% ; 46$ to 99 \\
\hline - USA, Japan & Insufficient data & $-N A-$ \\
\hline - Multicenter & $\begin{array}{l}87.2 \%(69.5-95.3) \\
4 \text { studies }\end{array}$ & $80 \% ; 4$ to 95 \\
\hline - Single-center & $\begin{array}{l}70.2 \%(52.1-83.5) \\
7 \text { studies }\end{array}$ & $87 \% ; 43$ to 93 \\
\hline $\begin{array}{l}\text { - >12-month follow- } \\
\text { up }\end{array}$ & $\begin{array}{l}79.5 \%(47.7-94.3) \\
3 \text { studies }\end{array}$ & $68 \% ; 3$ to 98 \\
\hline $\begin{array}{l}\text { - <12-month follow- } \\
\text { up }\end{array}$ & $\begin{array}{l}84.2 \%(53-96.2) \\
3 \text { studies }\end{array}$ & $93 \% ; 2$ to 98 \\
\hline Clinical success & $\begin{array}{l}89.2 \%(82.1-93.7) \\
18 \text { studies }\end{array}$ & $73 \%$; 50 to 98 \\
\hline - Japan & $\begin{array}{l}92.5 \%(83.9-96.7) ; \\
9 \text { studies }\end{array}$ & $50 \% ; 44$ to 99 \\
\hline - Europe & $\begin{array}{l}76.2 \%(58.9-87.7) ; \\
4 \text { studies }\end{array}$ & $76 \% ; 9$ to 99 \\
\hline - USA & Insufficient data & $-N A-$ \\
\hline $\begin{array}{l}\text { Others (multiple } \\
\text { countries, Israel, } \\
\text { India) }\end{array}$ & $\begin{array}{l}91 \%(80.2-96.2) ; \\
4 \text { studies }\end{array}$ & $0 \% ; 65$ to 98 \\
\hline
\end{tabular}

- Table 1 (Continuation)

\begin{tabular}{|c|c|c|}
\hline Outcome & $\begin{array}{l}\text { Pooled rate ( } 95 \% \\
\text { confidence interval) }\end{array}$ & $\begin{array}{l}\text { 12; } 95 \% \text { predic- } \\
\text { tion interval }\end{array}$ \\
\hline - Multicenter & $\begin{array}{l}90.2 \%(77.9-96) ; \\
5 \text { studies }\end{array}$ & $49 \% ; 47$ to 99 \\
\hline - Single-center & $\begin{array}{l}88.3 \%(79-93.8) ; \\
13 \text { studies }\end{array}$ & $71 \% ; 41$ to 98 \\
\hline - Manuscripts & $\begin{array}{l}89.6 \%(81.2-94.5) \\
14 \text { studies }\end{array}$ & $75 \% ; 45$ to 99 \\
\hline - Abstracts & $\begin{array}{l}88.8 \%(67.7-96.8) \\
4 \text { studies }\end{array}$ & $64 \% ; 7$ to 99 \\
\hline $\begin{array}{l}\text { - >12-month follow- } \\
\text { up }\end{array}$ & $\begin{array}{l}86.4 \%(71.9-94.1) \\
5 \text { studies }\end{array}$ & $71 \%$; 43 to 98 \\
\hline $\begin{array}{l}\text { - }<12 \text {-month follow- } \\
\text { up }\end{array}$ & $\begin{array}{l}85.3 \%(70.3-93.5) \\
6 \text { studies }\end{array}$ & $77 \% ; 42$ to 99 \\
\hline Adverse events (all) & $\begin{array}{l}18.1 \%(14.2-22.9) ; \\
22 \text { studies }\end{array}$ & $45 \% ; 8$ to 36 \\
\hline - Europe & $\begin{array}{l}18.7 \%(12.4-27.2) \\
5 \text { studies }\end{array}$ & $32 \% ; 6$ to 44 \\
\hline - Japan & $\begin{array}{l}15.8 \%(10.3-23.6) \\
9 \text { studies }\end{array}$ & $31 \% ; 5$ to 39 \\
\hline - USA & $\begin{array}{l}12.8 \%(7.4-21.3) \\
4 \text { studies }\end{array}$ & $0 \% ; 4$ to 40 \\
\hline $\begin{array}{l}\text { Others (multiple } \\
\text { countries, Israel, } \\
\text { India) }\end{array}$ & $\begin{array}{l}27.9 \%(19.4-38.2) \\
4 \text { studies }\end{array}$ & $48 \% ; 6$ to 70 \\
\hline - Multicenter & $\begin{array}{l}24.3 \%(16.8-33.7) \\
6 \text { studies }\end{array}$ & $51 \% ; 8$ to 55 \\
\hline - Single center & $\begin{array}{l}15.9 \%(11.8-21) \\
16 \text { studies }\end{array}$ & $30 \% ; 7$ to 31 \\
\hline - Manuscript & $\begin{array}{l}17.9 \%(13.4-23.5) ; \\
17 \text { studies }\end{array}$ & $50 \% ; 7$ to 39 \\
\hline - Abstracts & $\begin{array}{l}18.2 \%(10.8-29) \\
5 \text { studies }\end{array}$ & $32 \% ; 5$ to 49 \\
\hline \multicolumn{3}{|c|}{ Adverse events by ASGE Lexicon } \\
\hline - Mild & $\begin{array}{l}13 \%(8.3-19.9) ; \\
19 \text { studies }\end{array}$ & $69 \% ; 2$ to 49 \\
\hline - Moderate & $\begin{array}{l}9.9 \%(6.5-14.8) ; \\
19 \text { studies }\end{array}$ & $48 \% ; 3$ to 30 \\
\hline - Severe & $\begin{array}{l}3.9 \%(2.5-5.9) \\
19 \text { studies }\end{array}$ & $0 \% ; 2$ to 6 \\
\hline \multicolumn{3}{|c|}{ Post EUS-PDD individual adverse events } \\
\hline - Pancreatitis & $\begin{array}{l}6.6 \%(4.5-9.4) \\
21 \text { studies }\end{array}$ & $5 \% ; 4$ to 11 \\
\hline - Bleeding & $\begin{array}{l}4.1 \%(2.7-6.2) \\
21 \text { studies }\end{array}$ & $0 \% ; 3$ to 6 \\
\hline $\begin{array}{l}\text { - Perforation and/or } \\
\text { pneumoperitoneum }\end{array}$ & $\begin{array}{l}3.1 \%(1.9-5) ; 21 \\
\text { studies }\end{array}$ & $0 \% ; 2$ to 5 \\
\hline $\begin{array}{l}\text { - Pancreatic leak and/ } \\
\text { or pancreatic fluid } \\
\text { collection }\end{array}$ & $\begin{array}{l}2.3 \%(1.4-4) ; 21 \\
\text { studies }\end{array}$ & $0 \% ; 1$ to 4 \\
\hline
\end{tabular}


- Table 1 (Continuation)

\begin{tabular}{|c|c|c|}
\hline Outcome & $\begin{array}{l}\text { Pooled rate ( } 95 \% \\
\text { confidence interval) }\end{array}$ & $\begin{array}{l}\text { 12; } 95 \% \text { predic- } \\
\text { tion interval }\end{array}$ \\
\hline - Infection & $\begin{array}{l}2.8 \%(1.7-4.6) ; \\
21 \text { studies }\end{array}$ & $0 \% ; 2$ to 5 \\
\hline $\begin{array}{l}\text { - Nonspecific post- } \\
\text { procedure abdomi- } \\
\text { nal pain warranting } \\
\text { inpatient monitor- } \\
\text { ing }\end{array}$ & $\begin{array}{l}13.9 \%(8.2-22.6) \\
10 \text { studies }\end{array}$ & $65 \% ; 3$ to 49 \\
\hline $\begin{array}{l}\text { - Stent-related ad- } \\
\text { verse events }\end{array}$ & $\begin{array}{l}21.3 \%(11.5-36.2) ; \\
12 \text { studies }\end{array}$ & $85 \% ; 2$ to 80 \\
\hline - Reintervention & $\begin{array}{l}15.2 \%(9.1-24.1) \\
6 \text { studies }\end{array}$ & $44 \% ; 4$ to 45 \\
\hline Publication bias & Eggers $P=0.01$ & \\
\hline
\end{tabular}

\section{Publication bias}

Based on visual inspection of the funnel plot as well as quantitative measurement that used the Egger regression test, there was evidence of publication bias (funnel plot, Supplemental Fig. 7, Eggers two-tailed $P=0.01$ ). Further statistical analysis using the fail-Safe $\mathrm{N}$ test and Duval and Tweedie's 'Trim and Fill' test revealed that the reported pooled results would not be significantly affected by the unpublished studies.

\section{Discussion}

In this meta-analysis, EUS-PDD demonstrated high technical and clinical success rates, with acceptable AE rates. We report a pooled technical success rate of $84.8 \%$ with EUS-PDD, a pooled successful PD drainage rate of $77.5 \%$, and a pooled clinical success rate of $89.2 \%$. To the best of our knowledge, this is the first meta-analysis on this topic.

EUS-PDD continues to be one of the most challenging procedures in interventional EUS and the reasons are as follows: (1) even a dilated PD is smaller than a pancreatic fluid collection, the gallbladder, or even a dilated bile duct; (2) the stomach does not typically create a stable platform for an echoendoscope during EUS-PDD; and (3) currently, there are no dedicated PD stents designed for EUS-PDD.

Technically EUS-PDD can be done by the rendezvous method, wherein drainage can be achieved in either antegrade or retrograde fashion with or without stent placement. On the other hand, drainage can also be achieved in transmural/transluminal fashion by placement of a self-expanding metal stent (SEMS) and/or lumen apposing metal stent (LAMS). The feasibility, difficulty, and safety of EUS-PDD largely depend on the procedure methodology. A previous qualitative review suggested $91 \%$ technical success with transmural stenting and $72 \%$ with rendezvous [39]. Unfortunately, in this study, we were not able to classify the outcomes by the procedure methodology due to the fact that the included studies did not analyze outcomes in subgroups by procedure methodology.

Similarly, the clinical indication can also affect the feasibility and safety of EUS-PDD. EUS-PDD can be difficult to perform in chronic pancreatitis when compared to post-surgical anastomotic causes, due to the accompanying multiple strictures and calcifications in chronic pancreatitis. Studies did not stratify the outcomes based on the clinical indication and we acknowledge

\section{Successful PD drained}

\begin{tabular}{lllll} 
Study name & \multicolumn{4}{c}{ Statistics for each study } \\
& Event rate & Lower limit & Upper limit & Total \\
\hline Barkay, 2010 & 0.857 & 0.639 & 0.953 & $18 / 21$ \\
Chen, 2017 & 0.975 & 0.843 & 0.996 & $39 / 40$ \\
Dalal, 2020 & 0.848 & 0.714 & 0.926 & $39 / 46$ \\
Ergun, 2011 & 0.750 & 0.544 & 0.883 & $18 / 24$ \\
Fujii, 2013 & 0.711 & 0.564 & 0.824 & $32 / 45$ \\
Kurihara, 2013 & 0.882 & 0.632 & 0.970 & $15 / 17$ \\
Shah, 2012 & 0.345 & 0.232 & 0.479 & $19 / 55$ \\
Tessier, 2007 & 0.917 & 0.771 & 0.973 & $33 / 36$ \\
Tyberg, 2017 & 0.888 & 0.798 & 0.940 & $71 / 80$ \\
Vila, 2012 & 0.579 & 0.356 & 0.774 & $11 / 19$ \\
Will, 2015 & 0.468 & 0.378 & 0.561 & $52 / 111$ \\
& 0.775 & 0.631 & 0.874 &
\end{tabular}

\section{Event rate and $95 \% \mathrm{CI}$}

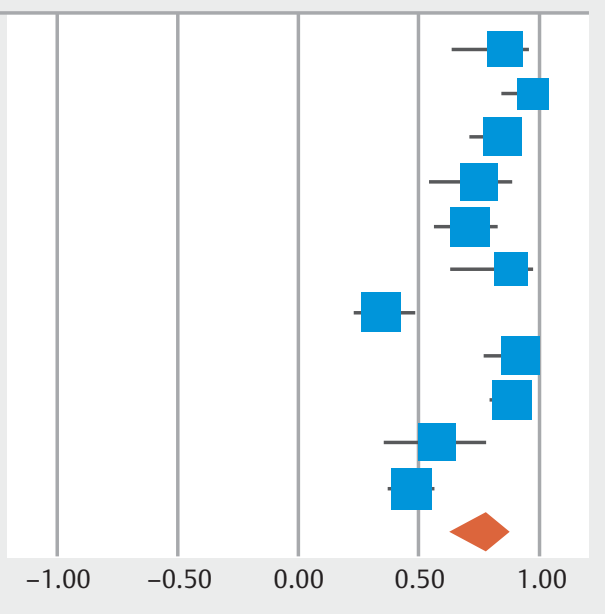

- Fig. 2 Forest plot of pooled successful PD drainage. 


\section{Clinical success}

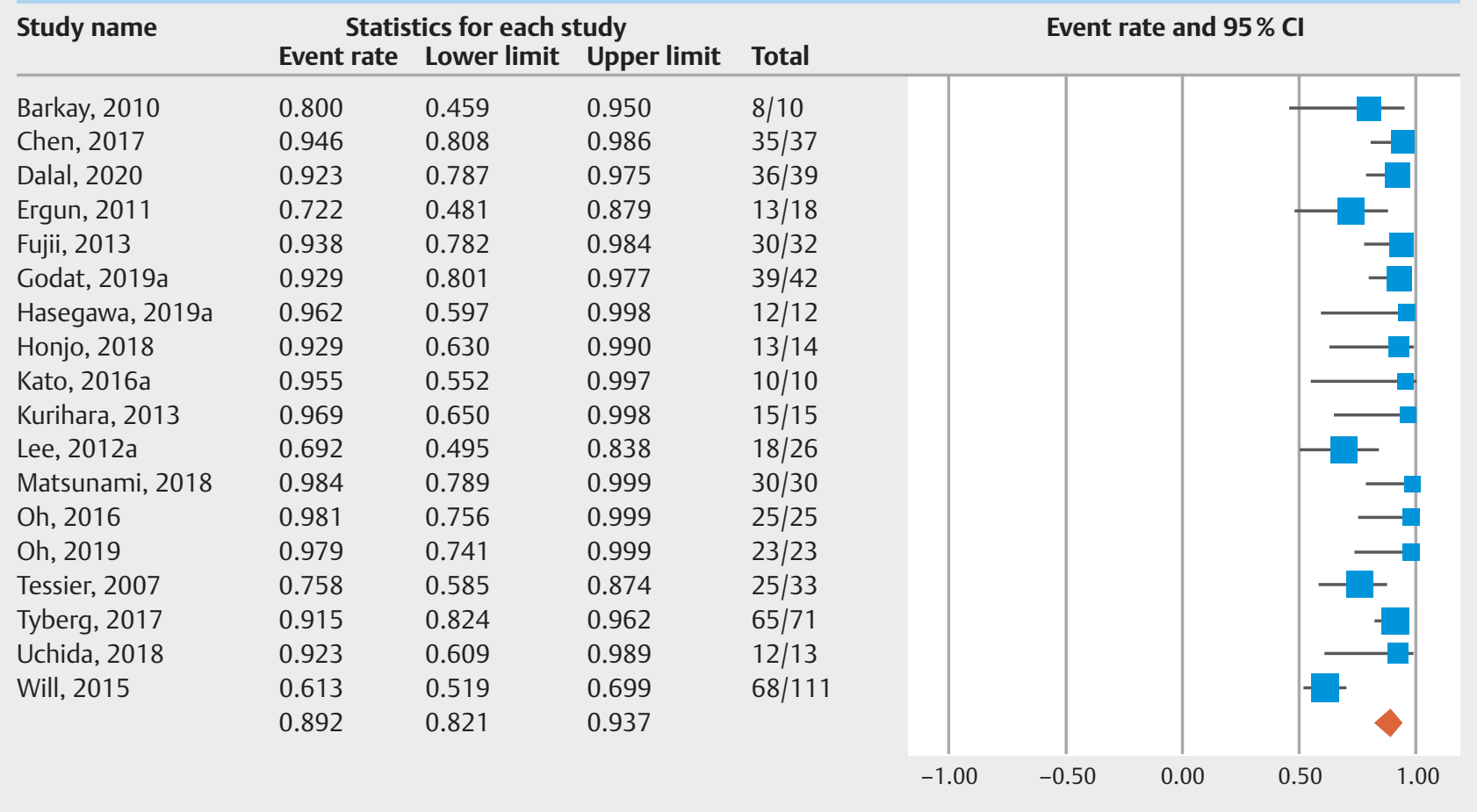

Fig. 3 Forest plot of pooled clinical success.

\section{Adverse events (all reported)}

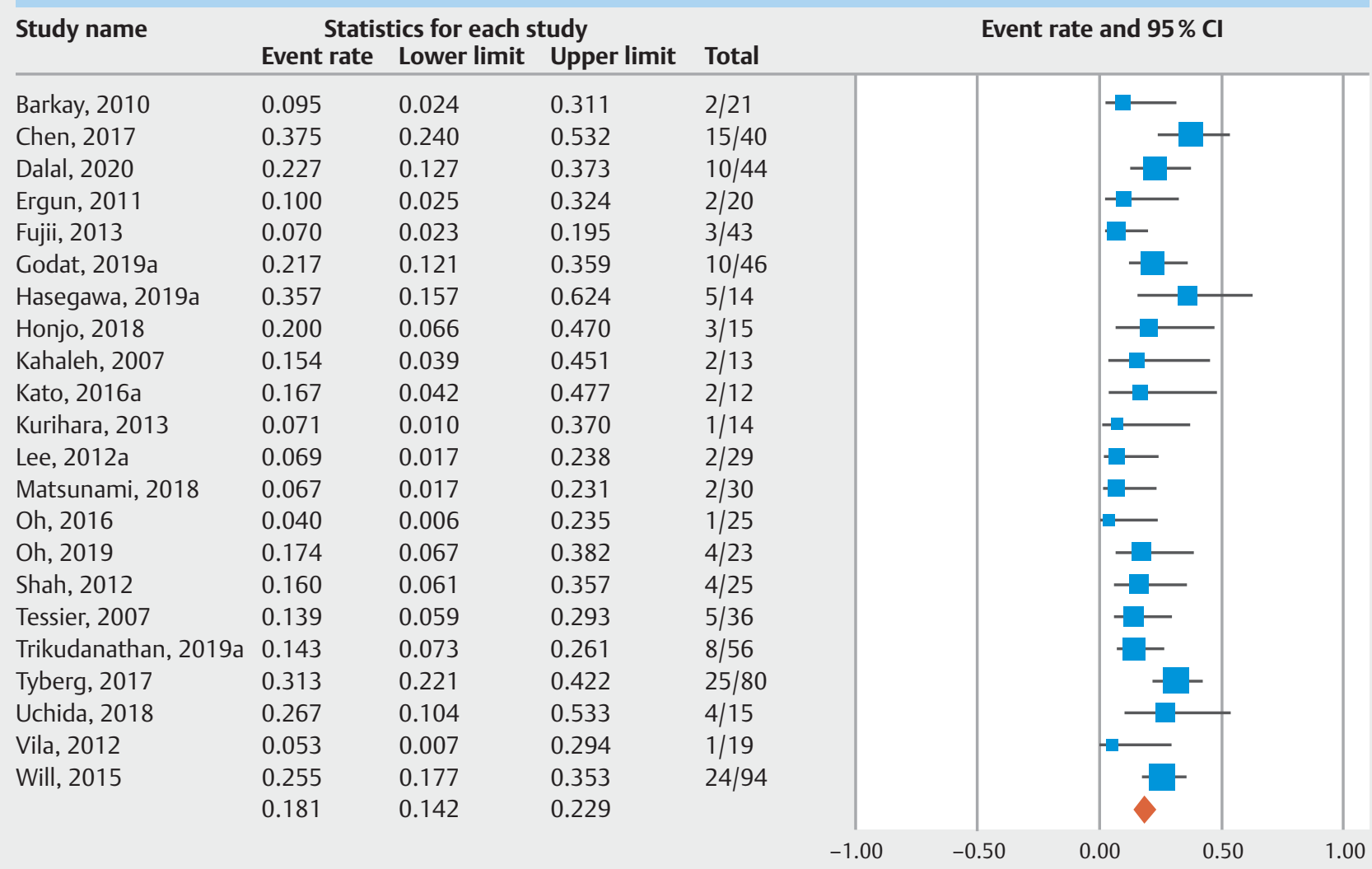

- Fig.4 Forest plot of pooled adverse events. 
this limitation. Nevertheless, we attempted to analyze the effects of clinical indications (chronic pancreatitis and post-surgical anastomosis) and EUS-PDD technique (transmural stenting and rendezvous drainage) by meta-regression analysis. We did not find any statistically significant influence on the outcomes from transmural stenting, rendezvous drainage, and chronic pancreatitis as single variables. However, EUS-PDD in post-surgical anastomosis demonstrated significant effect on the technical success (Knapp-Hartung two-tailed $P=0.03$ ), indicating that the technical success of EUS-PDD seemed to be better in postsurgical anastomosis patients. It is important to note that meta-regression analysis is a weak statistic in terms of assessing the predictability of patient variables and additionally the $\mathrm{R}^{2}$ goodness-of-fit was only $29 \%$ in our analysis.

Studies defined clinical success as resolution of symptoms, especially pain. In this study we noted the pooled rate of clinical success to $89 \%$, which was greater than the technical success and/or the rate of successful PD drained. Although the exact explanations are unclear for this finding, concurrent pain management by conservative methods like use of analgesics and alternative procedures like celiac plexus nerve blocks might have helped achieve resolution of pain in addition to EUS-PDD. Therefore, we cannot be certain that the reported clinical success rate is entirely due to EUS-PDD procedure.

To assess the safety of EUS-PDD, we analyzed the pooled rate of AEs in multiple angles. The pooled rate of all AEs together was $18.1 \%$. The pooled rate of pancreatitis was $6.6 \%$, bleeding was $4.1 \%$, perforation and/or pneumo-peritoneum was $3.1 \%$, pancreatic leak and/or pancreatic fluid collection was $2.3 \%$, and infection was $2.8 \%$. Based on the ASGE lexicon for endoscopic AEs, the pooled rate of mild AEs was $13 \%$, moderate was $9.9 \%$ and severe was $3.9 \%$. There were no procedure-related deaths. It is important to note that all studies were done at tertiary care centers by advanced therapeutic endoscopists. Stent-related AEs (stent occlusion and/or stent migration) were seen in $21.3 \%$ of patients and reintervention was required in $15.2 \%$ of patients.

The strengths of this review are as follows: systematic literature search with well-defined inclusion criteria, careful exclusion of redundant studies, inclusion of good quality studies with detailed extraction of data, and rigorous evaluation of study quality. There are limitations to this study, most of which are inherent to any meta-analysis. The included studies were not entirely representative of the general population and community practice, with most studies being performed in tertiarycare referral centers. Our analysis had studies that were retrospective in nature contributing to selection bias.

Our analysis has the limitation of heterogeneity. However, based on our sensitivity analysis and subgroup analyses, we have attempted to provide plausible explanations. Variability in the geography where studies were conducted, clinical indication for EUS-PDD, and differences in procedural techniques seemed to explain the heterogeneity. Other possible causes that we were not able to study were details of stenting (choice, type, and number used), and the differences in procedural tools across centers and countries. Finally, our study did not compare EUS-PDD to other techniques such as enteroscopy-assisted
ERCP (e-ERCP). Chen et al performed a multicenter trial comparing the two and reported a technical success rate of $92.5 \%$ and clinical success rate of $87.5 \%$ with EUS-PDD compared to $20 \%$ and $23.1 \%$, respectively, with e-ERCP. Nevertheless, this study is the best available in the literature thus far quantitatively summarizing the clinical outcomes of EUS-PDD.

\section{Conclusion}

In conclusion, based on our meta-analysis, EUS-PDD achieved a technical success rate of $84.8 \%$, a successful PD drainage rate of $77.5 \%$, and a clinical success rate of $89.2 \%$. The rate of moderate AEs was $9.9 \%$ and severe AEs were $3.9 \%$. Pancreatitis was the most commonly observed $\mathrm{AE}$ at $6.6 \%$. Owing to its technical complexity, EUS-PDD should be performed at advanced tertiary care centers with adequate expertise. Future studies are warranted to stratify the results in terms of clinical indication and EUS-PDD technique and study the efficacy of newer procedural tools including LAMS in EUS-PDD.

\section{Acknowledgement}

The authors thank Dana Gerberi, MLIS, Librarian, Mayo Clinic Libraries, for help with the systematic literature search.

\section{Competing interests}

Dr. Adler is a consultant for Boston Scientific

\section{References}

[1] Baars JE, Chen F, Sandroussi C et al. EUS-guided pancreatic duct drainage: Approach to a challenging procedure. Endosc Ultrasound 2018; 7: 284-285

[2] Giovannini M. EUS-guided pancreatic duct drainage: ready for prime time? Gastrointestinal endoscopy 2013; 78: 865-867

[3] Dumonceau J-M, Devière J, Le Moine O et al. Endoscopic pancreatic drainage in chronic pancreatitis associated with ductal stones: longterm results. Gastrointest Endosc 1996; 43: 547-555

[4] Adams DB, Ford MC, Anderson MC. Outcome after lateral pancreaticojejunostomy for chronic pancreatitis. Ann Surg 1994; 219: 481-489

[5] François E, Kahaleh M, Giovannini M et al. EUS-guided pancreaticogastrostomy. Gastrointest Endosc 2002; 56: 128-133

[6] Barkay O, Sherman S, McHenry L et al. Therapeutic EUS-assisted endoscopic retrograde pancreatography after failed pancreatic duct cannulation at ERCP. Gastrointest Endosc 2010; 71: 1166-1173

[7] Chen YI, Levy M], Moreels TG et al. An international multicenter study comparing EUS-guided pancreatic duct drainage with enteroscopyassisted endoscopic retrograde pancreatography after Whipple surgery. Gastrointest Endosc 2017; 85: 170-177

[8] Dalal A, Patil G, Maydeo A. Six-year retrospective analysis of endoscopic ultrasonography-guided pancreatic ductal interventions at a tertiary referral center. Digest Endosc 2020; 32: 409-416

[9] Ergun M, Aouattah T, Gillain C et al. Endoscopic ultrasound-guided transluminal drainage of pancreatic duct obstruction: long-term outcome. Endoscopy 2011; 43: 518-525 
[10] Fujii LL, Topazian MD, Abu Dayyeh BK et al. EUS-guided pancreatic duct intervention: outcomes of a single tertiary-care referral center experience. Gastrointest Endosc 2013; 78: 854-864.e1

[11] Godat S, David G, Maxime R et al. Endoscopic ultra-sonography guided drainage of the main pancreatic duct: A Swiss multi-center experience. Swiss Med Weekly 2019; 149: 11-12

[12] Hasegawa S, Sato T, Kubota K et al. Usefulness of endoscopic ultrasonography-guided pancreatic duct drainage for patients in ERCP failure with pancreatitis due to obstruction of pancreatic duct. Pancreas 2019; 48: 1439-1440

[13] Honjo M, Itoi T, Tsuchiya T et al. Safety and efficacy of ultra-tapered mechanical dilator for EUS-guided hepaticogastrostomy and pancreatic duct drainage compared with electrocautery dilator (with video). Endosc Ultrasound 2018; 7: 376-382

[14] Kahaleh M, Hernandez A], Tokar J et al. EUS-guided pancreaticogastrostomy: analysis of its efficacy to drain inaccessible pancreatic ducts. Gastrointest Endosc 2007; 65: 224-230

[15] Kato H, Mizukawa S, Yabe $S$ et al. The feasibility and effectiveness of EUS-guided pancreatic duct drainage. Pancreatology 2016; 16: S16S17

[16] Kurihara T, Itoi T, Sofuni A et al. Endoscopic ultrasonography-guided pancreatic duct drainage after failed endoscopic retrograde cholangiopancreatography in patients with malignant and benign pancreatic duct obstructions. Digest Endosc 2013; 25: 109-116

[17] Lee SS, Jang JW, Park DH. EUS-guided pancreatic duct drainage for symptomatic patients with pancreatic duct obstruction who are unsuitable for transpapillary drainage: Long-term follow-up results. Gastrointest Endosc 2012; 1: 845

[18] Matsunami Y, Itoi T, Sofuni A et al. Evaluation of a new stent for EUSguided pancreatic duct drainage: long-term follow-up outcome. Endoscopy International Open 2018; 6: E505-E512

[19] Oh D, Park DH, Cho MK et al. Feasibility and safety of a fully covered self-expandable metal stent with antimigration properties for EUSguided pancreatic duct drainage: early and midterm outcomes (with video). Gastrointest Endosc 2016; 83: 366-373

[20] Oh D, Park DH, Song T] et al. Long-term outcome of endoscopic ultrasound-guided pancreatic duct drainage using a fully covered selfexpandable metal stent for pancreaticojejunal anastomosis stricture. J Gastroenterol Hepatol 2020; 35: 994-1001

[21] Shah JN, Marson F, Weilert F et al. Single-operator, single-session EUSguided anterograde cholangiopancreatography in failed ERCP or inaccessible papilla. Gastrointest Endosc 2012; 75: 56-64

[22] Tessier G, Bories E, Arvanitakis M et al. EUS-guided pancreatogastrostomy and pancreatobulbostomy for the treatment of pain in patients with pancreatic ductal dilatation inaccessible for transpapillary endoscopic therapy. Gastrointest Endosc 2007; 65: 233-241

[23] Trikudanathan G, Dirweesh A, Attam R et al. EUS-guided pancreatic duct intervention: Technical outcomes at a single tertiary care center. Pancreas 2019; 48: 1537
[24] Tyberg A, Sharaiha RZ, Kedia P et al. EUS-guided pancreatic drainage for pancreatic strictures after failed ERCP: a multicenter international collaborative study. Gastrointest Endosc 2017; 85: 164-169

[25] Uchida D, Kato H, Saragai Y et al. Indications for endoscopic ultrasound-guided pancreatic drainage: for benign or malignant cases? Can J Gastroenterol Hepatol 2018; 2018: 8216109

[26] Vila JJ, Perez-Miranda M, Vazquez-Sequeiros E et al. Initial experience with EUS-guided cholangiopancreatography for biliary and pancreatic duct drainage: a Spanish national survey. Gastrointest Endosc 2012; 76: $1133-1141$

[27] Will U, Reichel A, Fueldner F et al. Endoscopic ultrasonography-guided drainage for patients with symptomatic obstruction and enlargement of the pancreatic duct. World J Gastroenterol 2015; 21: 1314013151

[28] Stroup DF, Berlin JA, Morton SC et al. Meta-analysis of observational studies in epidemiology: a proposal for reporting Meta-analysis Of Observational Studies in Epidemiology (MOOSE) group. JAMA 2000; 283: 2008-2012

[29] Moher D, Liberati A, Tetzlaff J et al. Preferred reporting items for systematic reviews and meta-analyses: The prisma statement. Ann Intern Med 2009; 151: 264-269

[30] Stang A. Critical evaluation of the Newcastle-Ottawa scale for the assessment of the quality of nonrandomized studies in meta-analyses. Eur J Epidemiol 2010; 25: 603-605

[31] Cotton PB, Eisen GM, Aabakken L et al. A lexicon for endoscopic adverse events: report of an ASGE workshop. Gastrointest Endosc 2010; 71: 446-454

[32] DerSimonian R, Laird N. Meta-analysis in clinical trials. Control Clin Trials 1986; 7: 177-188

[33] Sutton AJ, Abrams KR, Jones DR et al. Methods for meta-analysis in medical research. John Wiley \& Sons Ltd., New York 2000: 205-228

[34] Higgins J, Thompson SG, Spiegelhalter DJ. A re-evaluation of randomeffects meta-analysis. J R Stat Soc 2009; 172: 137-159

[35] Mohan BP, Adler DG. Heterogeneity in systematic review and metaanalysis: how to read between the numbers. Gastrointest Endosc 2019; 89: 902-903

[36] Higgins JP, Thompson SG, Deeks JJ et al. Measuring inconsistency in meta-analyses. BMJ 2003; 327: 557

[37] Duval S, Tweedie R. Trim and Fill: A simple funnel-plot-based method of testing and adjusting for publication bias in meta-analysis. Biometrics 2000; 56: 455-463

[38] Rothstein HR, Sutton AJ, Borenstein M. Publication bias in meta-analysis: Prevention, assessment and adjustments. New York: John Wiley \& Sons Ltd; 2006

[39] Itoi T, Kasuya K, Sofuni A et al. Endoscopic ultrasonography-guided pancreatic duct access: Techniques and literature review of pancreatography, transmural drainage and rendezvous techniques. Digest Endosc 2013; 25: 241-252 